\title{
In situ synchrotron tensile investigations on 14 YWT, MA957, and 9-Cr ODS alloys
}

Jun-Li Lin ${ }^{\mathrm{a}}$, Kun Mo ${ }^{\mathrm{b}, *}$, Di Yun ${ }^{\mathrm{b}}$, Yinbin Miao ${ }^{\mathrm{a}}$, Xiang Liu ${ }^{\mathrm{a}}$, Huijuan Zhao ${ }^{\mathrm{e}}$, David T. Hoelzer ${ }^{\mathrm{c}}$, Jun-Sang Park ${ }^{\mathrm{d}}$, Jonathan Almer ${ }^{\mathrm{d}}$, Guangming Zhang ${ }^{\mathrm{f}}$, Zhangjian Zhou ${ }^{\mathrm{f}}$, James F. Stubbins ${ }^{\mathrm{a}}$, Abdellatif M. Yacout ${ }^{\mathrm{b}}$

${ }^{a}$ University of Illinois at Urbana-Champaign, Urbana, IL, USA

${ }^{b}$ Nuclear Engineering Division, Argonne National Laboratory, Argonne, IL, USA

${ }^{c}$ Materials Science \& Technology Division, Oak Ridge National Laboratory, Oak Ridge, TN, USA

dAdvanced Photon Source, Argonne National Laboratory, Argonne, IL, USA

${ }^{\mathrm{e}}$ Mechanical Engineering Department, Clemson University, Clemson, SC, USA

${ }^{\mathrm{f}}$ School of Materials Science and Engineering, University of Science and Technology Beijing, Beijing 10083, China

*Corresponding author

Tel: +1 6302527417

Fax: +1 6302525161

E-mail address: kunmo@anl.gov

Submitted for publication in Journal of Nuclear Materials

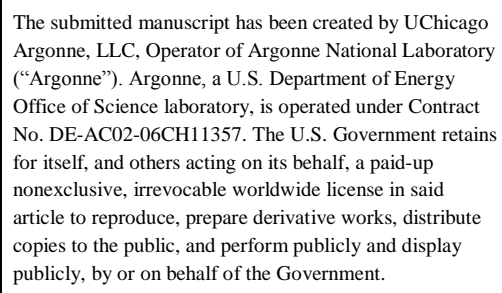




\begin{abstract}
Advanced ODS alloys provide exceptional radiation tolerance and high-temperature mechanical properties when compared to traditional ferritic and ferritic/martensitic (F/M) steels. Their remarkable properties result from ultrahigh density and ultrafine size of Y-Ti-O nanoclusters within the ferritic matrix. In this work, we applied a high-energy synchrotron radiation X-ray to study the deformation process of three advanced ODS materials including 14YWT, MA957, and 9-Cr ODS steel. Only the relatively large nanoparticles in the 9-Cr ODS were observed in the synchrotron X-ray diffraction. The nanoclusters in both 14 YWT and MA957 were invisible in the measurement due to their non-stoichiometric nature. Due to the different sizes of nanoparticles and nanoclusters in the materials, the Orowan looping was considered to be the major strengthening mechanism in the 9-Cr ODS, while the dispersed-barrier-hardening is dominant strengthening mechanism in both 14YWT and MA957, This analysis was inferred from the different build-up rates of dislocation density when plastic deformation was initiated. Finally, the dislocation densities interpreted from the X-ray measurements were successfully modeled using the Bergström's dislocation models.
\end{abstract}

\title{
Keywords:
}

Advanced ODS alloys; Dislocation density; Deformation; In-situ tensile test; High-energy X-ray diffraction 


\section{Introduction}

The increasing world-wide energy demand has encouraged both fossil and nuclear plants to improve the energy efficiency while maintaining environmental integrity [1]. Developing advanced nuclear systems, e.g. Generation IV nuclear reactors [2], is of significant importance to produce clean and reliable energy in the near future. The in-core components in the advanced nuclear systems are expected to resist higher temperatures and higher radiation during reactor operation. In this regard, recent nuclear research is directed to develop structural and fuelcladding materials with excellent resistances to radiations and high-temperatures. One of the potential candidates is oxide dispersion-strengthened (ODS) alloy [3-5]. These metallic materials exhibit better radiation resistance and high-temperature mechanical properties when compared to conventional ferritic/martensitic steels $[6,7]$. The improved material properties result from the key features within the alloys: the nano-scale oxide particles (nanoparticles). Depending on the fabrication procedure and heat treatment, the achieved microstructure (phase(s) of matrix, grain size, type and size of nanoparticles) varies greatly. This leads to an extensive range of ODS alloys that have the potential to be applied to various reactor environments. [3, 5, 8-10]. In some advanced ODS alloys, ultra-fine $(2-5 \mathrm{~nm})$ nanoparticles with a high density of $\mathrm{Y}-$, Ti- and Oatoms are uniformly distributed within the metallic matrix [11-14]. This unique nanostructure is known as nanocluster (NC) $[8,11,15]$. Beyond conventional ODS materials, the nanoclusters have a fully coherent interface with a metallic matrix, and thus efficiently decrease the number of microcracks that are often generated on the particle-matrix interface when applying external stress on the alloys [15]. The fracture toughness is thereby enhanced. McClintock et al. has conducted a set of mechanical tests for EUROFER 97 steel (a 9-Cr-W reduced ferritic/martensitic (F/M) steel [16]), ODS-EUROFER steel, and 14YWT alloy. Among these alloys, 14YWT showed the highest tensile strength and fracture toughness, and the lowest fracture toughness transition temperature in both irradiated and unirradiated conditions [15]. 
High-energy synchrotron X-ray has been extensively used to characterize microstructural development during in-situ mechanical or thermal tests for a variety of materials [17-28]. Materials' microstructural information is stored in the diffraction patterns that can be interpreted using different methods. For example, the shifting of diffraction peaks following applied stresses can be measured to calculate the evolution of lattice strain of different phases, and can be further used to predict the equivalent macroscopic strain of a material [29]. Subsequently, the internal stresses/loads can be calculated from the measured lattice strains. The divergence of internal loading of different phases has been found in many multi-phase alloys, and was often referred to the load partitioning behavior [18-20, 26, 30]. Young et al. investigated the load partitioning between ferrite and cementite for ultrahigh-carbon steel (UHCS) [18]. Using similar methods, Pan et al., [31] and Wang et al. [32, 33] have investigated different types of ferritic/martensitic (F/M) steels to study lattice strain evolution and load partitioning between matrix and its precipitation phases $\left(\mathrm{M}_{23} \mathrm{C}_{6}\right.$ carbides and $\left.\mathrm{Nb}(\mathrm{C}, \mathrm{N})\right)$. More recently, Mo et al. studied the load partitioning behavior between Fe matrix and oxide particles for a 9-Cr ODS steel, and observed the internal stress on nanoparticles increased to $\sim 3.5 \mathrm{GPa}$ with an external applied stress of only $\sim 986 \mathrm{MPa}$ [26]. The debonding of particles from the matrix was also observed with the evidence of rapidly decreasing internal stress on nanoparticles during sample necking.

In addition to the shift of diffraction peak, the width of diffraction peaks may contain even more in-depth microstructural information [33, 34]. For crystalline metallic materials, the peak broadening is generally caused by the deviation of a perfect crystal, mainly from two components: grain (or particle) size and lattice distortion. Both components can be extracted through analyzing the diffraction line profile $[35,36]$. If dislocations are assumed to be the major 
source of lattice distortion, the dislocation density in metallic phase can be further interpreted. Williamson-Hall (W-H) analysis [36] has been proved to be an effective method to separate the size broadening and strain broadening, and has been used to determine the grain size and dislocation density for many materials, e.g. Grade 91 and 92 F/M alloys [33, 34], irradiated HT9 steels [37], and ODS materials [28, 38].

In this study, the high-energy synchrotron X-ray diffraction was applied to three advanced nuclear structural materials: (1) 9-Cr ODS F/M steel; (2) MA957 ODS alloy; and (3) 14 YWT ODS alloy. The microstructural development in different stress-strain states during in-situ tensile tests was analyzed. The present work aims to better understand the microstructural evolution which can be inferred to the influence of the nano-features (nanoparticles/nanoclusters) in the materials.

\section{Materials and experimental procedure}

Three different advanced Fe-based materials including 14YWT, MA957 and 9-Cr ODS were investigated in this study. The 14YWT (SM170 heat, i.e. SM12d heat in previous publications [39]) alloy is a ODS ferritic alloy with the nominal composition: Fe-14Cr-3W-0.4Ti-0.3 $\mathrm{Y}_{2} \mathrm{O}_{3}$ (wt.\%). The MA957 is another ODS ferritic alloy but with minor compositions of Mo rather than $\mathrm{W}$ in 14YWT. The nominal composition of MA957 is $14 \mathrm{Cr}-1 \mathrm{Ti}-0.3 \mathrm{Mo}-0.25 \mathrm{Y}_{2} \mathrm{O}_{3}$ (wt.\%). The third material is a 9-Cr ODS steel with the nominal composition of Fe-9Cr-0.1C-1.5W-0.2 $\mathrm{V}$ $0.5 \mathrm{Ti}-0.35 \mathrm{Y}_{2} \mathrm{O}_{3}(\mathrm{wt} . \%)$. More details about this steel can be found in ref. [26, 40]. The grain size of 14YWT, 9-Cr ODS, and MA957 is 730nm [41], 500nm[40], and 500nm (from a recent TEM measurement; an example shown in fig. 1), respectively. The average nanoparticle size within the materials is $\sim 4 \mathrm{~nm}, \sim 10 \mathrm{~nm}$ and $\sim 5 \mathrm{~nm}$ for the 14YWT, 9-Cr ODS, and MA957, respectively. 


\section{(Insert Figure 1)}

The in-situ tensile tests with high-energy X-ray diffraction measurements were carried out at the 1-ID beamline at the Advanced Photon Source (APS) at Argonne National Laboratory (ANL). Figure 2 shows the experiment setup. Uniaxial tensile tests were conducted using an MTS closedloop servo-hydraulic test frame (model 858) with a maximum force of $\pm 15 \mathrm{kN}[42,43]$. The SSJ3 type tensile specimens, with a gauge section of $1.2 \mathrm{~mm} \times 0.75 \mathrm{~mm} \times 5 \mathrm{~mm}$ (width $\times$ thickness $\times$ length) were subjected to increasing uniaxial tensile stresses up to failure with a strain rate of $2 \times 10^{-4} \mathrm{~s}^{-1}$. Diffraction measurements were performed every 7 seconds by using a monochromatic $86 \mathrm{keV}(\lambda=0.0144 \mathrm{~nm}) \mathrm{X}$-ray beam with a beam size of $100 \times 100 \mu \mathrm{m}^{2}$. The distance between the sample and the detector was $\sim 1.4 \mathrm{~m}$.

(Insert Figure 2)

\section{Result}

\subsection{Phase identification}

Figure 3 shows the typical integrated X-ray diffraction line profile for 14YWT, MA957 and 9-Cr ODS. For the studied alloys, all major diffraction peaks of $\alpha$-Fe matrix were identified, while the minor phases including TiN and $\mathrm{Y}_{2} \mathrm{Ti}_{2} \mathrm{O}_{7}$ were only observed in 9-Cr ODS steel. The $\mathrm{Y}_{2} \mathrm{Ti}_{2} \mathrm{O}_{7}$ are the nanoscale particles within the 9-Cr ODS, while TiN are the larger particles within the steel. Details of the microstructure of the 9-Cr ODS can be found in ref. [26]. In the 9-Cr ODS, the

lattice constants for the matrix, TiN, and $\mathrm{Y}_{2} \mathrm{Ti}_{2} \mathrm{O}_{7}$ were measured to be $2.871 \AA$, $4.24 \AA$, and $10.11 \AA$, respectively. The lattice constant of the matrix for both 14YWT and MA957 was 2.873Å.

(Insert Figure 3) 


\subsection{Lattice strain evolution}

The engineering stress-strain diagrams of the materials are shown in Fig. 4. 14YWT has the highest strength among the three studied materials. Both MA957 and 9Cr-ODS have a relatively low strength but better ductility.

\section{(Insert Figure 4)}

The lattice strains of $\alpha$-Fe matrix are calculated based on the development of Debye-Sherrer rings (Fig. 5 (a-c)) during the tensile tests. When an external load is applied, the radius of the ring is decreased in the loading direction, and is increased in the direction perpendicular to the load due to Possion's effect. The lattice strain $\left(\varepsilon_{\text {lattice }}\right)$ is determined with the corresponding d-spacing by the equation 1 [44]:

$\varepsilon_{\text {lattice }}=\frac{d_{\sigma}^{\phi}-d_{0}}{d_{0}}$

Eq. 1

where $d_{\sigma}^{\phi}$ is the d-spacing of a $h k l$ reflection measured at a specific applied stress $\sigma$ and at the specific azimuthal angle $\phi$ of the Debye ring. The applied stress on the specimen is approximated by the true stress. The $d_{0}$ is the reference d-spacing of a $h k l$ reflection determined by linear fitting of the values of $d^{90}$ and $d^{0}$ during the elastic deformation of a material, and finding $d_{0}$ as the interaction of two fitted lines [26]. All the samples in this study show strong texture (Fig. 5 (a-c)), and thus the Debye-scherrer rings of some reflections, i.e. $\{200\}$ in 14YWT and $\{211\}$ in MA957, are not completed. For those reflections, Bragg conditions at the $\phi$ of $90^{\circ}$ (or $270^{\circ}$ ) and $0^{\circ}$ (or $180^{\circ}$ ) are not met, and thus these reflections are not convenient to use to study lattice strain development. Figure 5 (d-f) shows the lattice strain development of some representative reflections of the alloys. The elastic modulus of each measured reflection is determined by 
measuring the slope of lattice strain vs. applied stress in the elastic regime. (Table 1) Similar to many of the materials with multiple phases, the lattice strain of the metallic matrix of the studied alloys slightly decreased during early yielding, but increased afterwards until necking [18-20, 26].

\section{(Insert Figure 5)}

(Insert Table 1)

\subsection{Peak broadening}

In addition to lattice strain analysis based on the shift of the diffraction peaks, more information of microstructure development can be interpreted from the diffraction peaks broadening during the tensile tests. The full-width at half maximum (FWHM) of diffraction peak is commonly used to determine the peak width. In this study, the FWHM of diffraction peaks was determined by subtracting the instrumental broadening from the measured peak breadth. Instrumental broadening was measured using a NIST standard $\mathrm{LaB}_{6}$ sample. The diffraction peaks were fit using a Pseudo-Voigt function. The evolutions of FWHM of several $\alpha$-Fe reflections of the alloys are shown in Fig. 6. Little changes in FWHMs were observed during elastic deformation before sample yielding, while the diffraction peaks significantly broadened during plastic deformation. This indicated that the peak broadening was mainly caused by microstructural development during plastic deformation, including the increase in dislocation population due to strain hardening, and changes in coherent scattering volume due to the dislocation structure evolution, e.g. forming of dislocation cell structures.

\section{(Insert Figure 6)}

\section{Discussion}

\subsection{Nanoparticle structures}


Although all three types of advanced alloys contained nano-scale particles, only those in the 9-Cr ODS were observed in this study using synchrotron X-ray diffraction. No minor phases were observed in either 14YWT or MA957 in the synchrotron measurement. (Fig. 3) This observation agreed with previous high-energy wide-angle X-ray scattering on the SM12d heat (i.e. SM170 in this study) of 14YWT alloy, where no visible diffraction peaks from Yi-Ti-O phases were found [39]. Sakasegawa et al. have conducted systematic analyses on chemical composition and its relation to the size of nanoparticle and nanoclusters in a MA957 ODS alloy (note that the MA957 alloy in the present study is of different heat of the MA957 ODS alloy in refs. [45, 46]). It was observed that non-stoichiometric $\mathrm{Y}_{\mathrm{x}} \mathrm{Ti}_{\mathrm{y}} \mathrm{O}_{\mathrm{z}}$ enriched clusters were in the size of $\sim 2$ to $\sim 15 \mathrm{~nm}$ $(\mathrm{Y} / \mathrm{Ti}<1)$, and stoichiometric $\mathrm{Y}_{2} \mathrm{Ti}_{2} \mathrm{O}_{7}$ particles were in the size of $\sim 15$ to $\sim 35 \mathrm{~nm}$. Brandes et al. suggested that the nanoclusters in the size of $2-4 \mathrm{~nm}$ in $14 \mathrm{YWT}$ were amorphous [47]. In the present study, the average size of the nanoparticle/nanocluster is $\sim 4 \mathrm{~nm}, \sim 5 \mathrm{~nm}, \sim 10 \mathrm{~nm}$ for 14YWT, MA957, and 9-Cr ODS, respectively. Here, the schematic of the particle size distribution in different "domains of nanoparticle structure $[45,46]$ " is shown in Fig. 7. Note that the range of the particle size is arbitrary but is centered in the average particle size for each material. The more accurate range and distribution of nanoparticle size in these materials are currently being analyzed using atom probe tomography (APT), and are not reported in this paper. Nevertheless, since the nanoparticles in the 9-Cr ODS are much larger than those in 14YWT and MA957, many of the nanoparticle are beyond the range of non-stoichiometric limit, i.e. $\sim 15 \mathrm{~nm}$. These relatively large particles could be observed by X-ray diffraction due to their stoichiometric nature (the cubic $\mathrm{Y}_{2} \mathrm{Ti}_{2} \mathrm{O}_{7}$ structure). In contrast, the average particle size in the clusters in 14YWT and MA957 are much smaller than the non-stoichiometric limit, thus the majority of nanoparticles are non-stoichiometric, or possibly amorphous, which were invisible in X-ray diffraction. The present synchrotron X-ray diffraction measurement further supports the studies by Sakasegawa et al. and Brandes et al. Moreover, the X-ray diffraction volume in this study was $75 \times 10^{5} \mu \mathrm{m}^{3}$, composed of numerous particles. This bulk measurement provided better statistics 
compared to the smaller scale TEM-based measurements.

(Insert Figure 7)

\subsection{Dislocation density evolution}

As aforementioned in section 3.3, micro-strain and coherent scattering volume are two major mechanisms that impact the width of diffraction peaks during deformation. The sum of two broadening mechanisms can be separated by Williamson-Hall (W-H) equation [36]:

$\Delta K=\frac{0.9}{D}+\Delta K^{D}$

Eq. 2

where $\Delta K^{D}$ is the contribution of micro-strain, and $D$ is the contribution of average grain or particle size to peak broadening. Here, $K=2 \sin \theta / \lambda, \Delta K^{D}=2 \cos \theta(\Delta \theta) / \lambda ; \theta, \lambda$ and $\Delta \theta$ are the diffraction angle, the wavelength of the X-ray, and the FWHM of the diffraction peak, respectively. Ungar et al. [48] and Groma et al. [49] further improved the function of analyzing diffraction line-profile for large crystals containing dislocations, and Eq.3 was then rewritten as:

$\Delta K=\frac{0.9}{D}+\left(\pi A b^{2} / 2\right)^{1 / 2} \rho^{1 / 2}\left(K C^{1 / 2}\right)+\left(\pi A^{\prime} b^{2} / 2\right)^{1 / 2} Q^{1 / 2}\left(K^{2} C\right)$

A new scaling factor $C$ on the line profile, which is termed elastic contrast factor, has been introduced into the W-H equations. $A$ is the parameter determined by the effective outer cutoff radius of the dislocation, is chosen to be 2 for compatibility with a dislocation density of approximately $10^{15} \mathrm{~m}^{-2}$ [28]. Note that the interpreted dislocation densities agree well with the TEM measurement [50]. $b$ is Burgers vector. $A^{\prime}$ is an adjustable parameter similar to $A$. $Q$ is a correlation function between two particles in a dislocation ensemble, and can be given as the fluctuation of dislocation density [51]. The third term at the right-hand side of Eq. 3 is usually 
small and is ignored. Eq. 3 is called modified Williamson-Hall equation. By using this equation, the dislocation density can be analyzed by measuring the slope of the fitted plot line. This method has been successfully applied to and supported by many experimental works [25, 33, 48, 52-54].

In this study, the elastic contrast factors of $\alpha$-Fe were calculated by applying equations developed by Ungar et al. [55]. The elastic constants of $\mathrm{Fe}\left(\mathrm{C}_{11}=233 \mathrm{GPa}, \mathrm{C}_{12}=135 \mathrm{GPa}\right.$ and $\left.\mathrm{C}_{44}=118 \mathrm{GPa}\right)$ [56] were used in the calculation. The elastic contrast factors were then calculated based on most common $(110)<111>$ edge type and $<111>$ screw type dislocation in body-centered cubic (BCC) materials, and the fraction of dislocation was assumed 50\% edge and 50\% screw (the influence of this fraction on the dislocation density computation was small). Table 2 shows the calculated elastic contrast factors.

\section{(Insert Table 2)}

Figure 8 shows the modified $\mathrm{W}-\mathrm{H}$ plots of three materials before tensile loading and yielding. Good linearity was found in all three materials before and after deformation, indicating the diffraction peak broadening was mainly due to the increase in dislocation density [37]. The slope of fitted-line in modified $\mathrm{W}-\mathrm{H}$ plot is proportional to the dislocation density, and the y-intercept (at $\Delta K=0$ ) is inversed to the coherent scattering volume. The dislocation density was then interpreted based on the W-H slope, with an uncertainty of $~ 15 \%$ for the 14YWT and 9-Cr ODS samples and $\sim 17 \%$ for the MA957. To show the trend of dislocation density development during the tensile tests, we analyzed the relative dislocation density $\left(\rho^{\prime}\right)$ as: $\rho^{\prime}(\varepsilon)=\rho(\varepsilon) / \rho(\varepsilon=0)$. Figure 9 shows the relative dislocation density as a function of engineering strain during tensile tests. Two different regimes were observed in the evolution of the W-H slope during the tensile tests: (1) Regime I: dislocation density increases significantly ( $\sim 5$ to 6 times of the value before loading) before sample necking $\left(\sim 0.2 \%<\varepsilon<\sim \varepsilon_{U T S} ; \varepsilon_{U T S}\right.$ is the engineering strain at the ultimate 
tensile strength (UTS)); (2) Regime II: dislocation density stops increasing after necking $(\varepsilon>$ $\left.\varepsilon_{U T S}\right)$. The dislocation behavior in the Regime II was due to the X-ray beam was not probing in the necking region. Although these three types of advanced alloys had similar trends of dislocation density development, the dislocation density in the 9-Cr ODS built up faster than that in either 14YWT or MA957 when plastic deformation was initiated. Recent strengthening modeling on the 14YWT showed that the dispersed-barrier-hardening model provided a better estimation than Orowan by-pass hardening model [57]. This indicated the Y-,Ti-, and O-enriched nanoclusters were shearable, weak particles, compared to the relatively large, hard, and impenetrable nanoparticles in the 9-Cr ODS. The major strengthening mechanism in the 9-Cr ODS can be estimated as Orowan looping that produce a lot of dislocations during plastic deformation. Therefore, the dislocation population increased fastest in the 9-Cr ODS among the studied materials.

(Insert Figure 8)

(Insert Figure 9)

The contribution of dislocation to the overall flow stress, which is also called dislocation forest hardening, can be approximately modeled as [58]:

$\sigma=\sigma_{0}+M \alpha G b \sqrt{\rho}$ Eq. 4

where $\sigma_{0}$ is the stress needed for a dislocation to glide in the absence of other dislocations, $G$ is the shear modulus, $b$ is the length of the Burgers vector, and $\alpha$ is a material-dependent coefficient that characterizes the dislocation arrangement and movement mechanisms. Detailed discussion of the constant $\alpha$ can be found in [59]. This correlation of stress and dislocation density is directly demonstrated in Fig. 10: applied stress vs. W-H slope $(\propto \sqrt{\rho})$ for all three materials. Good linearity of the slope and applied stress was observed in the Regime I $\left(\sim 0.2 \%<\varepsilon<\sim \varepsilon_{U T S}\right)$ for all 
studied materials, indicating the dominance of dislocation glide in the plastic deformation.

(Insert Figure 10)

4.3. Modeling of dislocation density development during deformation

The evolution of dislocation density with true strain of materials was derived by Bergström [60]:

$\frac{d \rho(\varepsilon)}{d \varepsilon}=\frac{\bar{m}}{b s(\varepsilon)}-\Omega \rho(\varepsilon)$

Eq. 5

where $\rho$ is the dislocation density, $\varepsilon$ is the true strain of the material, $b$ is Burgers vector, $\bar{m}$ is Taylor's constant, $s$ is the mean free path of dislocation motion which is the average travel distance of dislocations before it was immobilized by interaction with microstructure, and $\Omega$ is the strain-independent dynamic recovery coefficient which represents the remobilization of immobile dislocations. This model has been successfully applied to many Fe-based materials [6064]. Assuming the mean free path of dislocation motion $(s)$ is independent of true strain $(\varepsilon)$, the solution of Eq. 5 is:

$\rho(\varepsilon)=\frac{\bar{m}}{b s \Omega}+\left(\rho_{0}-\frac{\bar{m}}{b s \Omega}\right) e^{-\Omega \varepsilon}$,

Eq. 6

where $\rho_{0}$ is the dislocation density at the beginning of tensile test, i.e. when $\varepsilon=0$. If the mean free path of dislocation $(s)$ is modeled to be true strain $(\varepsilon)$ dependent, $s(\varepsilon)$ can be given as [60]:

$s(\varepsilon)=s_{f}+\left(s_{0}-s_{f}\right) e^{-k \varepsilon}$,

By combing Eqs. 5\&7, the strain dependent dislocation density is then solved:

$\rho(\varepsilon)=e^{-\Omega \varepsilon}\left(\frac{\bar{m}}{b} \int^{\varepsilon} \frac{e^{\lambda \Omega}}{s_{f}+\left(s_{0}-s_{f}\right) e^{-k \lambda}} d \lambda\right)$

which can be further developed as: 
$\rho(\varepsilon)=e^{-\Omega \varepsilon}\left(-\frac{\bar{m}}{b} \frac{e^{\varepsilon(\Omega+k)}{ }_{2} F_{1}\left(1, \frac{\Omega+k}{\Omega} ; \frac{\Omega}{k}+2 ; \frac{e^{k \varepsilon} s_{f}}{s_{f}-s_{0}}\right)}{(\Omega+k)\left(s_{f}-s_{0}\right)}\right)$,

Eq. 9

where ${ }_{2} \mathrm{~F}_{1}$ is Gaussian hypergeometric function, which can be expanded by power series. By taking first two terms from power series with the condition of $\rho(\varepsilon=0)=\rho_{0}$, Eq. 9 becomes:

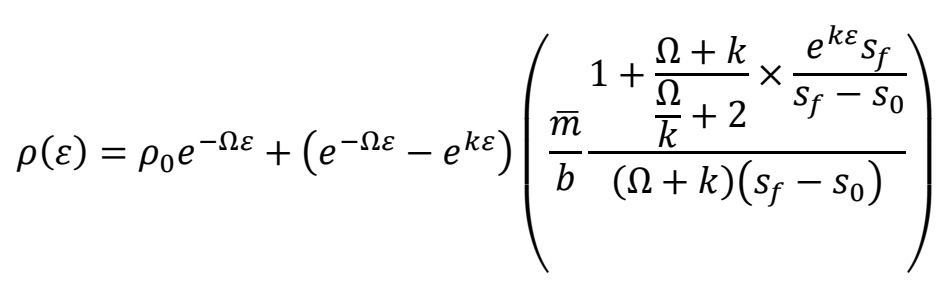

The evolution of dislocation density for the three types of alloys interpreted based on the modified W-H plot and Eq. 3 was modeled using Eqs. $6 \& 10(\bar{m}=2$ and $b=0.2912 \mathrm{~nm})$. In order to reduce the degree of freedom when refining the fit of Eq. 10, the values of $\Omega, s_{0}$ (dislocation mean free path when $\varepsilon=0$ ), and $\rho_{0}$ were obtained by fitting the experimental data to Eq. 6 first, and then using the obtained parameter values in Eq. 10 to perform another data fitting. The remaining parameters $\left(k, s_{0}\right.$ and $\left.s_{f}\right)$ were allowed to vary freely within reasonable physical limits $\left(k, s_{0}\right.$ and $s_{\mathrm{f}}$ must be greater than 0$) . k, s_{0}$ and $s_{f}$ were given reasonable start-values with repeated refinement of the fit to verify the convergence of the final values. The fitting results are summarized in Table 3 .

(Insert Table 3)

Figure 11 shows the modeling results compared with the experimental data. Both models (represented in Eq. 6 \&10) agree well with experimental data. The modeled zero-strain dislocation densities $\left(\rho_{0}\right)$ are in good agreement with values from X-ray measurement. Early studies on BCC iron and steels $[62,63]$ concluded that the value of $s$ only varied slightly during deformation. Nevertheless, in this work the model with strain dependent dislocation mean free path (Eq. 10) exhibits more consistency with the experimental data (evidenced by the smaller 
value of error sum of squares (SSE)) than the model with the constant value of $s$. The dislocation mean free path started at $s_{0}$ and decreased to the final value $s_{f}$ with transition rate controlled by the parameter $k$, as shown in Figure 12.

\section{(Insert Figure 11)}

(Insert Figure 12)

Note that the dislocation density was slightly decreasing after necking. This is apparent in the 14YWT and 9-Cr ODS. This decrease in dislocation density might attribute to the behavior of dislocation annihilation during tensile tests [65], which was mainly due to cross-slip of screw dislocations with opposites signs [66, 67] and has been observed in FCC [66], HCP [68, 69] and BCC [70] materials. This trend of decrease in dislocation density can only be caught by data fitting using Eq. 10, and thus it should be considered a better model of dislocation density evolution during tensile tests. In addition to Bergström's dislocation models, a model has been established by Kocks and Mecking [71] to describe the evolution of dislocation densities with strain in a relatively simple manner. The Kocks-Mecking concept assumes that dislocations are created and annihilated during plastic deformation. Modeling using Kocks-Mecking's method will be conducted and comparison to Bergström's dislocation models will be included in future work on the three advanced ferritic alloys.

\section{Conclusions}

In this study, high-energy synchrotron X-ray diffraction was applied to study three advanced nuclear structural materials including 14YWT ODS alloy, MA957 ODS alloy, and 9-Cr ODS steel. With tensile loading and in-situ X-ray exposure, time-resolved lattice strain and dislocation density development during deformation were clarified. Summary and conclusions of the synchrotron radiation study are given below: 
1. Among the three studied materials, only the relatively large nanoparticles in the 9-Cr ODS could be observed in the synchrotron X-ray diffraction. The nanoclusters in both 14 YWT and MA957 were invisible in the measurement due to their non-stoichiometric nature.

2. Based on the modified Williamson-Hall method, the dislocation density evolution during tensile tests was successfully interpreted from the diffraction peak broadening for all studied materials. The dislocation density increased significantly $(\sim 5$ to 6 times of the value before loading) before sample necking, and was in a linear relationship with flow stress which agreed with the empirical dislocation hardening theory ( $\sigma=\sigma_{0}+$ $M \alpha G b \sqrt{\rho})$.

3. The dislocation density in the 9-Cr ODS built up faster than that in either 14YWT or MA957 when plastic deformation was initiated. This observation implies the Orowan looping is the major strengthening mechanism for the 9-Cr ODS which contains relatively large nanoparticles. In contrast, the major strengthening mechanism in 14 YWT and MA957 is dispersed-barrier-hardening due the ultra-fine but sharable nanoclusters.

4. Based on Bergström's dislocation models, dislocation density evolutions of all studied materials were modeled with two different assumptions: (1) dislocation mean free path was strain independent (i.e. constant value of $s$ ); and (2) dislocation mean free path was strain dependent (i.e. $s(\varepsilon)$ ). Although both models provide good consistency with the dislocation density interpreted from X-ray measurements, only the model with strain dependent $s$ caught the phenomenon of slightly dislocation density decreasing after sample necking.

\section{Acknowledgements}

This work was supported by the Department of Energy, NEUP program under Award Number 
13-5408. Argonne National Laboratory's work was supported by the U.S. Department of Energy under Contract No. DE-AC-02-06CH11357 between UChicago Argonne, LLC and the Department of Energy. The author(s) gratefully acknowledge the support of the International Institute for Carbon Neutral Energy Research (WPI-I2CNER), sponsored by the World Premier International Research Center Initiative (WPI), MEXT, Japan. 


\section{References}

[1] S. Chu and A. Majumdar, "Opportunities and challenges for a sustainable energy future," Nature, vol. 488, pp. 294-303, 2012.

[2] "A Technology Roadmap for Generation IV Nuclear Energy Systems", U.S. DOE Nuclear Energy Research Advisory Committee and the Generation IV International Forum, 2002.

[3] G. R. Odette, M. J. Alinger, and B. D. Wirth, "Recent developments in irradiation-resistant steels," Annual Review of Materials Research, vol. 38, pp. 471-503, 2008.

[4] S. Ukai, S. Mizuta, M. Fujiwara, T. Okuda, and T. Kobayashi, "Development of 9Cr-ODS martensitic steel claddings for fuel pins by means of ferrite to austenite phase transformation," Journal of nuclear science and technology, vol. 39, pp. 778-788, 2002.

[5] S. Ukai and M. Fujiwara, "Perspective of ODS alloys application in nuclear environments," Journal of Nuclear Materials, vol. 307, pp. 749-757, 2002.

[6] A. Uehira, S. Ukai, T. Mizuno, T. Asaga, and E. Yoshida, "Tensile Properties of llCr-0.5 Mo-2W, V, Nb Stainless Steel in LMFBR Environment," Journal of nuclear science and technology, vol. 37, pp. 780-786, 2000.

[7] R. L. Klueh, "Reduced-activation steels: Future development for improved creep strength," Journal of Nuclear Materials, vol. 378, pp. 159-166, 2008.

[8] S. J. Zinkle and L. L. Snead, "Designing Radiation Resistance in Materials for Fusion Energy," Annual Review of Materials Research, Vol 44, vol. 44, pp. 241267, 2014.

[9] M. S. El-Genk and J. M. Tournier, "A review of refractory metal alloys and mechanically alloyed-oxide dispersion strengthened steels for space nuclear power systems," Journal of Nuclear Materials, vol. 340, pp. 93-112, 2005.

[10] E. A. Marquis, J. M. Hyde, D. W. Saxey, S. Lozano-Perez, V. de Castro, D. Hudson, et al., "Nuclear reactor materials at the atomic scale," Materials Today, vol. 12, pp. 30-37, 2009.

[11] M. K. Miller, E. A. Kenik, K. F. Russell, L. Heatherly, D. T. Hoelzer, and P. J. Maziasz, "Atom probe tomography of nanoscale particles in ODS ferritic alloys," Materials Science and Engineering: A, vol. 353, pp. 140-145, 2003.

[12] D. J. Larson, P. J. Maziasz, I. S. Kim, and K. Miyahara, "Three-dimensional atom probe observation of nanoscale titanium-oxygen clustering in an oxidedispersion-strengthened Fe-12Cr-3W-0.4 Ti+ Y203 ferritic alloy," Scripta materialia, vol. 44, pp. 359-364, 2001.

[13] M. K. Miller, D. T. Hoelzer, E. A. Kenik, and K. F. Russell, "Nanometer scale precipitation in ferritic MA/ODS alloy MA957," Journal of nuclear materials, vol. 329, pp. 338-341, 2004.

[14] I. S. Kim, J. D. Hunn, N. Hashimoto, D. L. Larson, P. J. Maziasz, K. Miyahara, et al., "Defect and void evolution in oxide dispersion strengthened ferritic steels under 3.2 MeV Fe+ ion irradiation with simultaneous helium injection," Journal of nuclear materials, vol. 280, pp. 264-274, 2000. 
[15] D. A. McClintock, M. A. Sokolov, D. T. Hoelzer, and R. K. Nanstad, "Mechanical properties of irradiated ODS-EUROFER and nanocluster strengthened 14YWT," Journal of Nuclear Materials, vol. 392, pp. 353-359, Jul 152009.

[16] B. Van der Schaaf, F. Tavassoli, C. Fazio, E. Rigal, E. Diegele, R. Lindau, et al., "The development of EUROFER reduced activation steel," Fusion Engineering and Design, vol. 69, pp. 197-203, 2003.

[17] D. R. Haeffner, J. D. Almer, and U. Lienert, "The use of high energy X-rays from the Advanced Photon Source to study stresses in materials," Materials Science and Engineering: A, vol. 399, pp. 120-127, 2005.

[18] M. L. Young, J. D. Almer, M. R. Daymond, D. R. Haeffner, and D. C. Dunand, "Load partitioning between ferrite and cementite during elasto-plastic deformation of an ultrahigh-carbon steel," Acta Materialia, vol. 55, pp. 19992011, 2007.

[19] P. Hedström, L. E. Lindgren, J. Almer, U. Lienert, J. Bernier, M. Terner, et al., "Load partitioning and strain-induced martensite formation during tensile loading of a metastable austenitic stainless steel," Metallurgical and Materials Transactions A, vol. 40, pp. 1039-1048, 2009.

[20] S. Cheng, Y. D. Wang, H. Choo, X. L. Wang, J. D. Almer, P. K. Liaw, et al., "An assessment of the contributing factors to the superior properties of a nanostructured steel using in situ high-energy X-ray diffraction," Acta Materialia, vol. 58, pp. 2419-2429, 2010.

[21] K. B. Colas, A. T. Motta, J. D. Almer, M. R. Daymond, M. Kerr, A. D. Banchik, et al., "In situ study of hydride precipitation kinetics and re-orientation in Zircaloy using synchrotron radiation," Acta Materialia, vol. 58, pp. 65756583, 2010.

[22] M. A. Weisser, A. D. Evans, S. Van Petegem, S. R. Holdsworth, and H. Van Swygenhoven, "In situ room temperature tensile deformation of a $1 \% \mathrm{CrMoV}$ bainitic steel using synchrotron and neutron diffraction," Acta Materialia, vol. 59, pp. 4448-4457, 2011.

[23] P. Schloth, M. A. Weisser, H. Van Swygenhoven, S. Van Petegem, P. Susila, V. Subramanya Sarma, et al., "Two strain-hardening mechanisms in nanocrystalline austenitic steel: An in situ synchrotron X-ray diffraction study," Scripta Materialia, vol. 66, pp. 690-693, 2012.

[24] R. Blondé, E. Jimenez-Melero, L. Zhao, J. P. Wright, E. Brück, S. van der Zwaag, et al., "High-energy X-ray diffraction study on the temperature-dependent mechanical stability of retained austenite in low-alloyed TRIP steels," Acta Materialia, vol. 60, pp. 565-577, 2012.

[25] L. Wang, M. Li, and J. Almer, "In situ characterization of Grade 92 steel during tensile deformation using concurrent high energy X-ray diffraction and small angle X-ray scattering," Journal of Nuclear Materials, vol. 440, pp. 81-90, 2013.

[26] K. Mo, Z. Zhou, Y. Miao, D. Yun, H.-M. Tung, G. Zhang, et al., "Synchrotron study on load partitioning between ferrite/martensite and nanoparticles of a 9Cr ODS steel," Journal of Nuclear Materials, vol. 455, pp. 376-381, 2014.

[27] W. Mohamed, D. Yun, K. Mo, M. J. Pellin, M. C. Billone, J. Almer, et al., "Depth profile of oxide volume fractions of Zircaloy- 2 in. high-temperature steam: 
An in-situ synchrotron radiation study," Journal of Nuclear Materials, vol. 454, pp. 192-199, 2014.

[28] Y. B. Miao, K. Mo, Z. J. Zhou, X. Liu, K. C. Lan, G. M. Zhang, et al., "In situ synchrotron tensile investigations on the phase responses within an oxide dispersion-strengthened (ODS) 304 steel," Materials Science and Engineering a-Structural Materials Properties Microstructure and Processing, vol. 625, pp. 146-152, 2015.

[29] M. R. Daymond, "The determination of a continuum mechanics equivalent elastic strain from the analysis of multiple diffraction peaks," Journal of applied physics, vol. 96, pp. 4263-4272, 2004.

[30] K. Mo, H.-M. Tung, M. Li, J. Almer, X. Chen, W. Chen, et al., "Synchrotron radiation study on Alloy 617 and Alloy 230 for VHTR application," Journal of Pressure Vessel Technology-Transactions of the Asme, vol. 135, paper No. 021502, 2013.

[31] X. Pan, X. Wu, K. Mo, X. Chen, J. Almer, J. Ilavsky, et al., "Lattice strain and damage evolution of $9--12 \% \mathrm{Cr}$ ferritic/martensitic steel during in situ tensile test by X-ray diffraction and small angle scattering," Journal of Nuclear Materials, vol. 407, pp. 10-15, 2010.

[32] l. Wang, M. Li, and J. Almer, "In situ characterization of Grade 92 steel during tensile deformation using concurrent high energy X-ray diffraction and small angle X-ray scattering," Journal of Nuclear Materials, vol. 440, pp. 81-90, 2013 2013.

[33] L. Y. Wang, M. Li, and J. Almer, "Investigation of deformation and microstructural evolution in Grade 91 ferritic-martensitic steel by in situ high-energy X-rays," Acta Materialia, vol. 62, pp. 239-249, 2014.

[34] M. Li, L. Y. Wang, and J. D. Almer, "Dislocation evolution during tensile deformation in ferritic-martensitic steels revealed by high-energy X-rays," Acta Materialia, vol. 76, pp. 381-393, 2014.

[35] B. E. Warren and B. L. Averbach, "The Effect of Cold-Work Distortion on XRay Patterns," Journal of Applied Physics, vol. 21, pp. 595-599, 1950.

[36] G. K. Williamson and W. H. Hall, "X-ray line broadening from filed aluminium and wolfram," Acta Metallurgica, vol. 1, pp. 22-31, 1953.

[37] P. L. Mosbrucker, D. W. Brown, O. Anderoglu, L. Balogh, S. A. Maloy, T. A. Sisneros, et al., "Neutron and X-ray diffraction analysis of the effect of irradiation dose and temperature on microstructure of irradiated HT-9 steel," Journal of Nuclear Materials, vol. 443, pp. 522-530, 2013.

[38] G. Zhang, Z. Zhou, K. Mo, Y. Miao, X. Liu, J. Almer, et al., "The evolution of internal stress and dislocation during tensile deformation in a $9 \mathrm{Cr}$ ferritic/martensitic (F/M) ODS steel investigated by high-energy X-rays," Journal of Nuclear Materials, vol. 467, pp. 50-57, 2015.

[39] J.-S. Park, X. Zhang, H. Sharma, P. Kenesei, D. Hoelzer, M. Li, et al., "Highenergy synchrotron $\mathrm{x}$-ray techniques for studying irradiated materials," Journal of Materials Research, vol. 30, pp. 1380-1391, 2015.

[40] G. Zhang, K. Mo, Y. Miao, X. Liu, J. Almer, Z. Zhou, et al., "Load partitioning between ferrite/martensite and dispersed nanoparticles of a $9 \mathrm{Cr}$ 
ferritic/martensitic (F/M) ODS steel at high temperatures," Materials Science and Engineering: A, vol. 637, pp. 75-81, 2015.

[41] D. T. Hoelzer, "FCRD ODS Materials Development - FCRD-NFA1," presented at the DOE-NE Materials Crosscut Coordination Meeting - 2013 Webinar, http://energy.gov/ne/downloads/2013-annual-doe-ne-materials-researchcoordination-meeting-0, 2013.

[42] D. D. Qu, K. D. Liss, Y. J. Sun, M. Reid, J. D. Almer, K. Yan, et al., "Structural origins for the high plasticity of a Zr--Cu--Ni--Al bulk metallic glass," Acta Materialia, vol. 61, pp. 321-330, 2013.

[43] K.-D. Liss and K. Yan, "Thermo-mechanical processing in a synchrotron beam," Materials science and engineering: $a$, vol. 528, pp. 11-27, 2010.

[44] B. B. He, "Introduction to two-dimensional X-ray diffraction," Powder diffraction, vol. 18, pp. 71-85, 2003.

[45] H. Sakasegawa, L. Chaffron, F. Legendre, L. Boulanger, T. Cozzika, M. Brocq, et al., "Correlation between chemical composition and size of very small oxide particles in the MA957 ODS ferritic alloy," Journal of Nuclear Materials, vol. 384, pp. 115-118, 2009.

[46] H. Sakasegawa, F. Legendre, L. Boulanger, M. Brocq, L. Chaffron, T. Cozzika, et al., "Stability of non-stoichiometric clusters in the MA957 ODS ferrtic alloy," Journal of Nuclear Materials, vol. 417, pp. 229-232, 2011.

[47] M. C. Brandes, L. Kovarik, M. K. Miller, and M. J. Mills, "Morphology, structure, and chemistry of nanoclusters in a mechanically alloyed nanostructured ferritic steel," Journal of Materials Science, vol. 47, pp. 3913-3923, 2012.

[48] T. Ungár and A. Borbély, "The effect of dislocation contrast on x-ray line broadening: A new approach to line profile analysis," Applied Physics Letters, vol. 69, pp. 3173-3175, 1996.

[49] I. Groma, T. Ungár, and M. Wilkens, "Asymmetric X-ray line broadening of plastically deformed crystals. I. theory," Journal of applied crystallography, vol. 21, pp. 47-54, 1988.

[50] J. Bentley and D. T. Hoelzer, "TEM Characterization of Tensile-Tested 14YWT Nanostructured Ferritic Alloys," Microscopy and Microanalysis, vol. 14, pp. 1416-1417, 2008.

[51] M. Wilkens, "The determination of density and distribution of dislocations in deformed single crystals from broadened X-ray diffraction profiles," physica status solidi (a), vol. 2, pp. 359-370, 1970.

[52] A. Khorsand Zak, W. H. Abd Majid, M. E. Abrishami, and R. Yousefi, "X-ray analysis of $\mathrm{ZnO}$ nanoparticles by Williamson--Hall and size--strain plot methods," Solid State Sciences, vol. 13, pp. 251-256, 2011.

[53] V. D. Mote, Y. Purushotham, and B. N. Dole, "Williamson-Hall analysis in estimation of lattice strain in nanometer-sized $\mathrm{ZnO}$ particles," Journal of Theoretical and Applied Physics, vol. 6, pp. 1-8, 2012.

[54] Y. Miao, K. Mo, Z. Zhou, X. Liu, K.-C. Lan, G. Zhang, et al., "On the microstructure and strengthening mechanism in oxide dispersionstrengthened 316 steel: A coordinated electron microscopy, atom probe tomography and in situ synchrotron tensile investigation," Materials Science and Engineering: A, vol. 639, pp. 585-596, 2015. 
[55] T. Ungár, I. Dragomir, Á. Révész, and A. Borbély, "The contrast factors of dislocations in cubic crystals: the dislocation model of strain anisotropy in practice," Journal of applied crystallography, vol. 32, pp. 992-1002, 1999.

[56] J. A. Rayne and B. S. Chandrasekhar, "Elastic constants of iron from 4.2 to 300 K," Physical Review, vol. 122, pp. 1714-1714, 1961.

[57] J. H. Kim, T. S. Byun, D. T. Hoelzer, C. H. Park, J. T. Yeom, and J. K. Hong, "Temperature dependence of strengthening mechanisms in the nanostructured ferritic alloy 14YWT: Part II-Mechanistic models and predictions," Materials Science and Engineering: A, vol. 559, pp. 111-118, 2013.

[58] J. E. Bailey and P. B. Hirsch, "The dislocation distribution, flow stress, and stored energy in cold-worked polycrystalline silver," Philosophical Magazine, vol. 5, pp. 485-497, 1960.

[59] H. Mughrabi, "A 2-Parameter Description of Heterogeneous Dislocation Distributions in Deformed Metal Crystals," Materials Science and Engineering, vol. 85, pp. 15-31, 1987.

[60] Y. Bergström, Y. Granbom, and D. Sterkenburg, "A dislocation-based theory for the deformation hardening behavior of DP steels: impact of martensite content and ferrite grain size," Journal of Metallurgy, vol. 2010, 2010.

[61] Y. Bergström and W. Roberts, "The application of a dislocation model to dynamical strain ageing in \$-iron containing interstitial atoms," Acta Metallurgica, vol. 19, pp. 815-823, 1971.

[62] Y. Bergström and H. Hallén, "An improved dislocation model for the stressstrain behaviour of polycrystalline \$-Fe," Materials Science and Engineering, vol. 55, pp. 49-61, 1982.

[63] Y. Bergström, "A dislocation model for the stress-strain behaviour of polycrystalline \$-Fe with special emphasis on the variation of the densities of mobile and immobile dislocations," Materials science and engineering, vol. 5, pp. 193-200, 1970.

[64] W. Roberts, S. Karlsson, and Y. Bergström, "The rate of dislocation multiplication in polycrystalline iron," Materials Science and Engineering, vol. 11, pp. 247-254, 1973.

[65] U. Essmann and H. Mughrabi, "Annihilation of dislocations during tensile and cyclic deformation and limits of dislocation densities," Philosophical Magazine A, vol. 40, pp. 731-756, 1979.

[66] A. Seeger, J. Diehl, S. Mader, and H. Rebstock, "Work-hardening and worksoftening of face-centred cubic metal crystals," Philosophical Magazine, vol. 2, pp. 323-350, 1957.

[67] S. Mader and A. Seeger, "Untersuchung des Gleitlinienbildes Kubischflächenzentrierter einkristalle," Acta metallurgica, vol. 8, pp. 513-522, 1960.

[68] J. V. Sharp, M. J. Makin, and J. W. Christian, "Dislocation structure in deformed single crystals of magnesium," physica status solidi (b), vol. 11, pp. 845-864, 1965.

[69] P. B. Hirsch and J. S. Lally, "The deformation of magnesium single crystals," Philosophical Magazine, vol. 12, pp. 595-648, 1965. 
[70] D. K. Bowen, J. W. Christian, and G. Taylor, "Deformation properties of niobium single crystals," Canadian Journal of Physics, vol. 45, pp. 903-938, 1967.

[71] U. F. Kocks and H. Mecking, "Physics and phenomenology of strain hardening: the FCC case," Progress in Materials Science, vol. 48, pp. 171-273, 2003. 
Figure 1. The bright field TEM image of the MA 957 alloy

Figure 2. Schematic of the synchrotron experimental setup

Figure 3. X-ray diffraction line profile of 14YWT, MA957 and 9-Cr ODS. All of the diffraction peaks of the metallic matrix were identified. The minor phases (e.g. TiN) and nanoparticles were only observed in the 9-Cr ODS. The d-spacing regime ranging from $\sim 2.3$ to $\sim 3.1$ is enlarged in order to show the peaks of $\mathrm{Y}_{2} \mathrm{Ti}_{2} \mathrm{O}_{7}$ with relatively weak intensity.

Figure 4. Engineering stress-strain diagrams for 9-Cr ODS, MA957 and 14YWT

Figure 5. 2D diffraction pattern of (a) 14YWT; (b) MA957; \& (c) 9-Cr ODS. Applied stress vs. lattice strain for the metallic matrix of: (d) 14YWT; (e) MA957; \& (f) 9-Cr ODS. $\varepsilon_{22}$ and $\varepsilon_{l l}$ are the lattice strains perpendicular and parallel to the applied stress, respectively. The errors of the lattice strain values are smaller than $\pm 5 \times 10^{-4}$.

Figure 6. Evolution of FWHM for (a) 14YWT, (b) MA957 and (c) 9-Cr ODS. Yield strength (YS) is indicated by black dashed line. (Note: each pixel is $0.2 \mathrm{~mm} \times 0.2 \mathrm{~mm}$ )

Figure 7. The schematic of the particle size distribution on the "domains of nanoparticle structure $[42,43] "$

Figure 8. Modified W-H plots based on Eq. 3 before tensile loading for (a) 14YWT, (b) MA957 and (c) 9-Cr ODS; and during sample yielding for (d) 14YWT, (e) MA957 and (f) 9-Cr ODS

Figure 9. Relative dislocation density (\%) vs. engineering strain during tensile tests. The uncertainty in dislocation density for the three materials was obtained by propagation from both the diffraction peak measurement and the modified $\mathrm{W}-\mathrm{H}$ fitting. The uncertainty was found to be $\sim 15 \%$ for the 14YWT and 9-Cr ODS, and $\sim 17 \%$ for the MA957.

Figure 10. Applied stress vs. W-H slope for (a) 14YWT, (b) MA957 and (c) 9-Cr ODS

Figure 11. Modeling of dislocation density with true strain for (a) 14YWT, (b) MA957 and (c) 9Cr ODS. The red curve shows the results based on Eq. 6 ( $s$ is $\varepsilon$ independent); the black curve shows the results based on Eq. 10 ( $s$ is $\varepsilon$ dependent).

Figure 12. Evolution of dislocation mean free path $s(\varepsilon)$ as a function of true strain. 


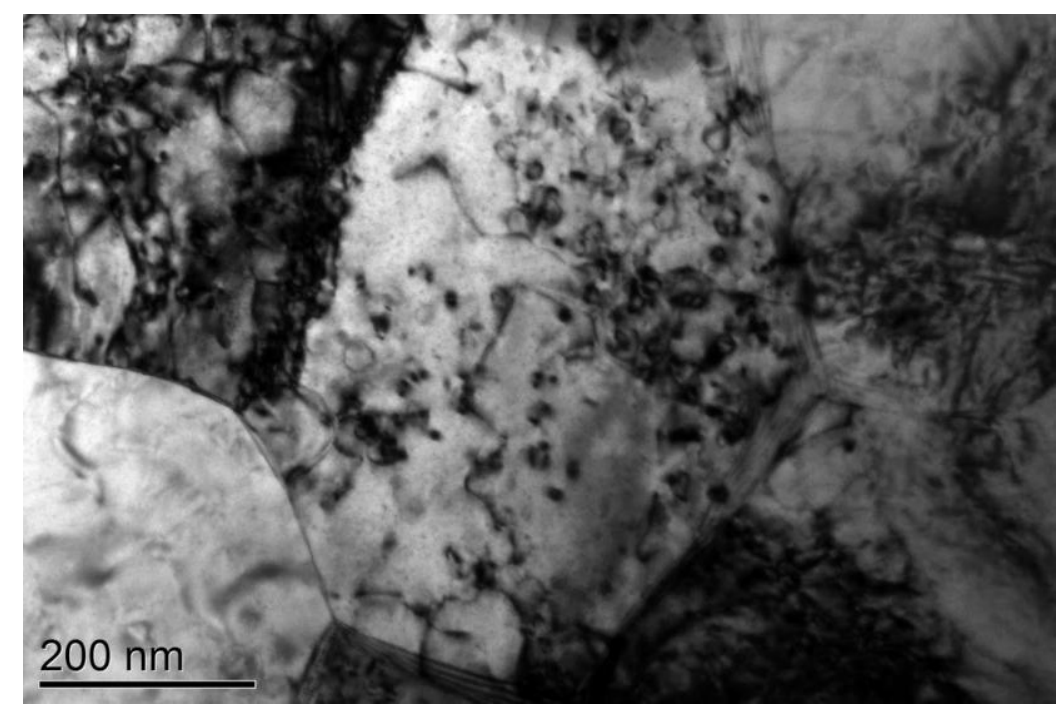

(Figure 1) 


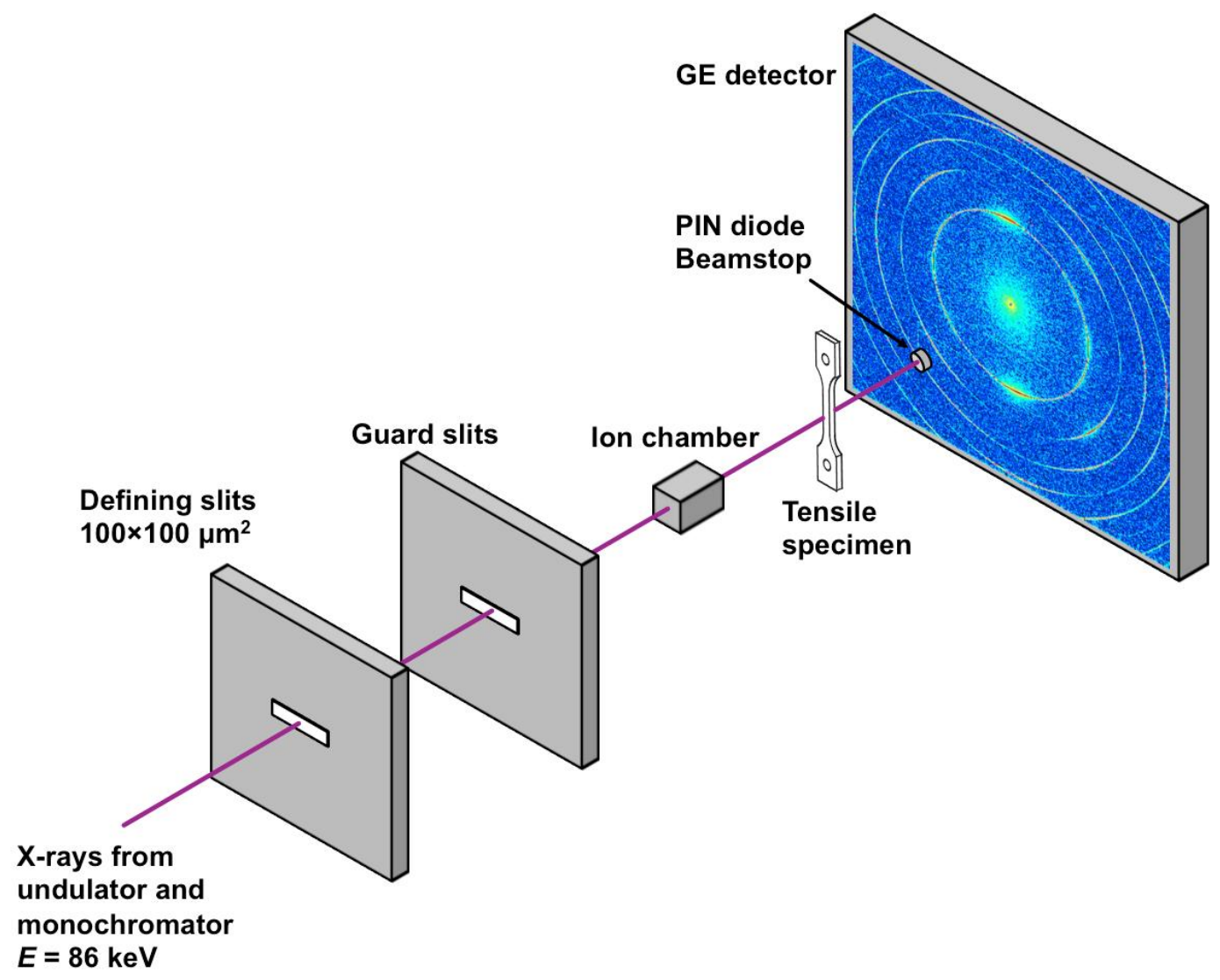

(Figure 2) 


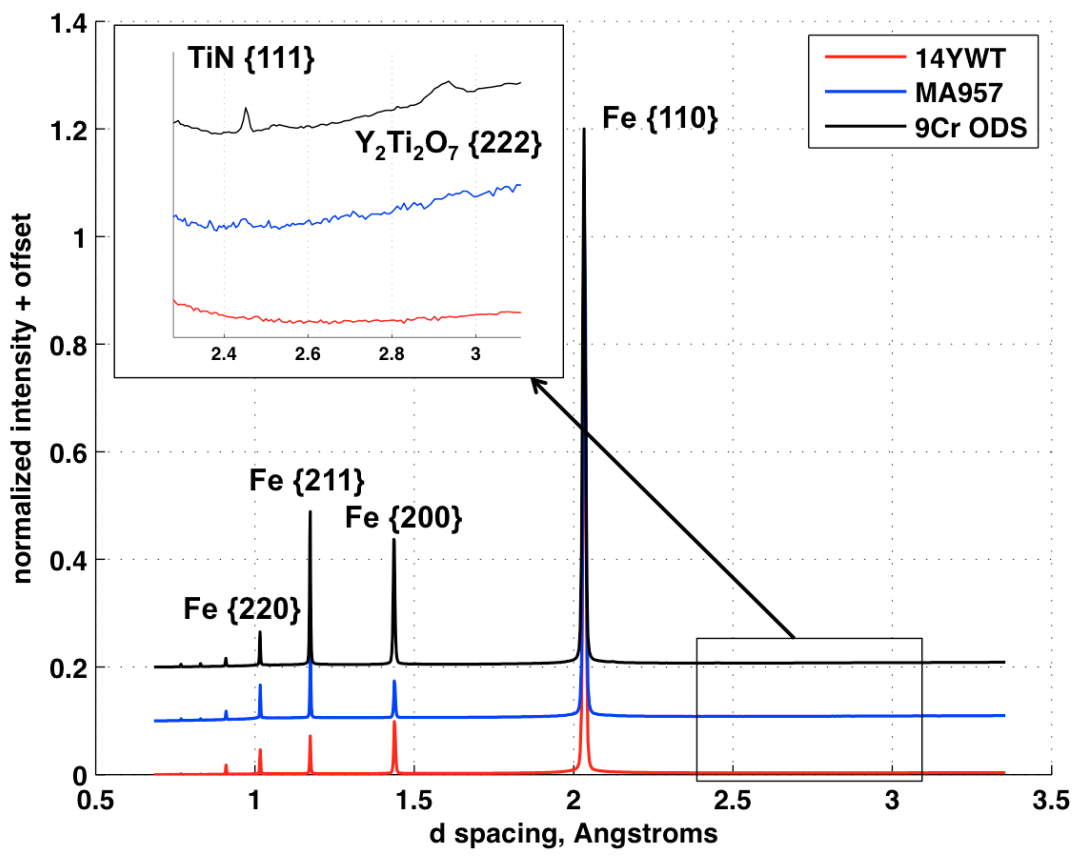

(Figure 3) 


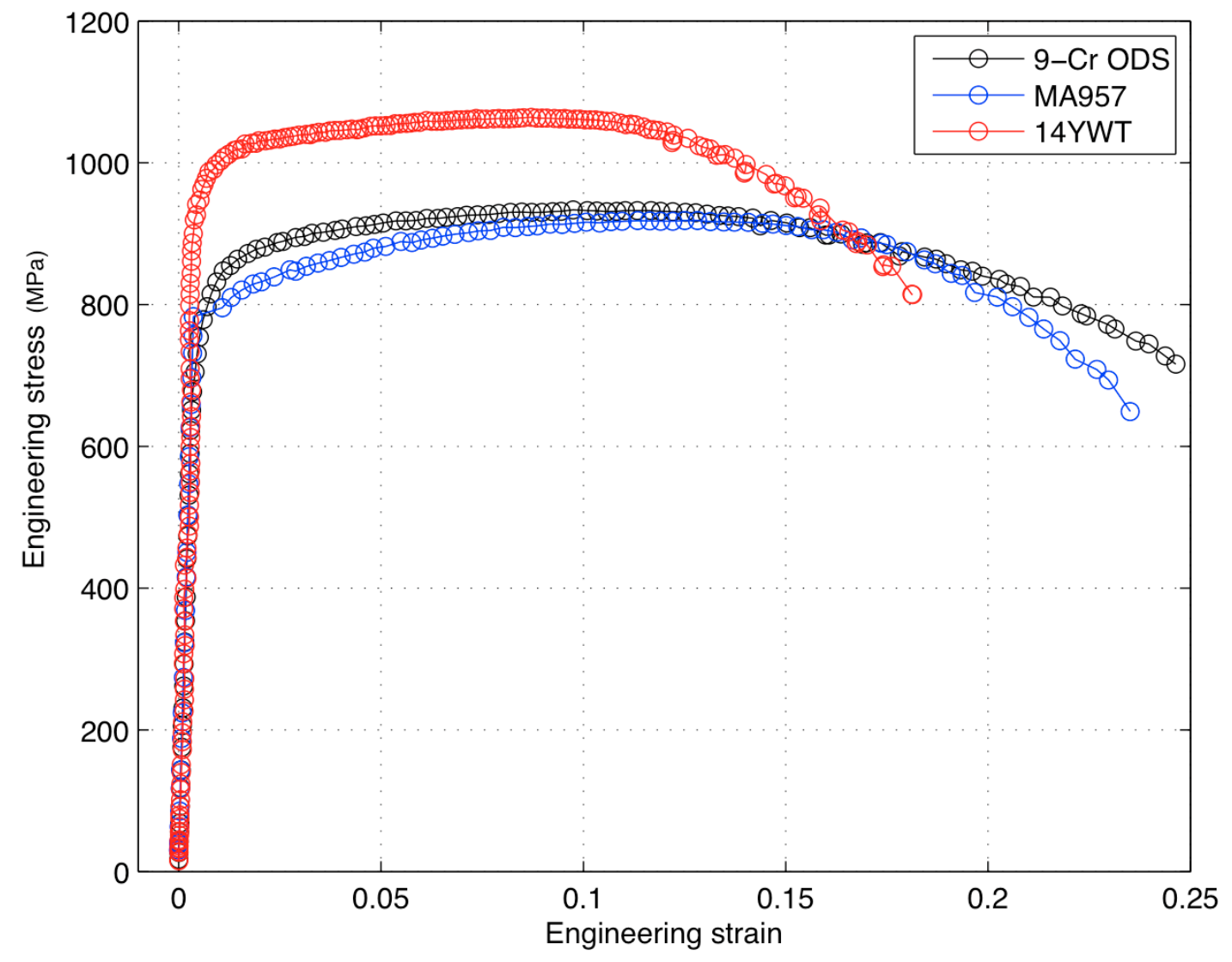

(Figure 4) 

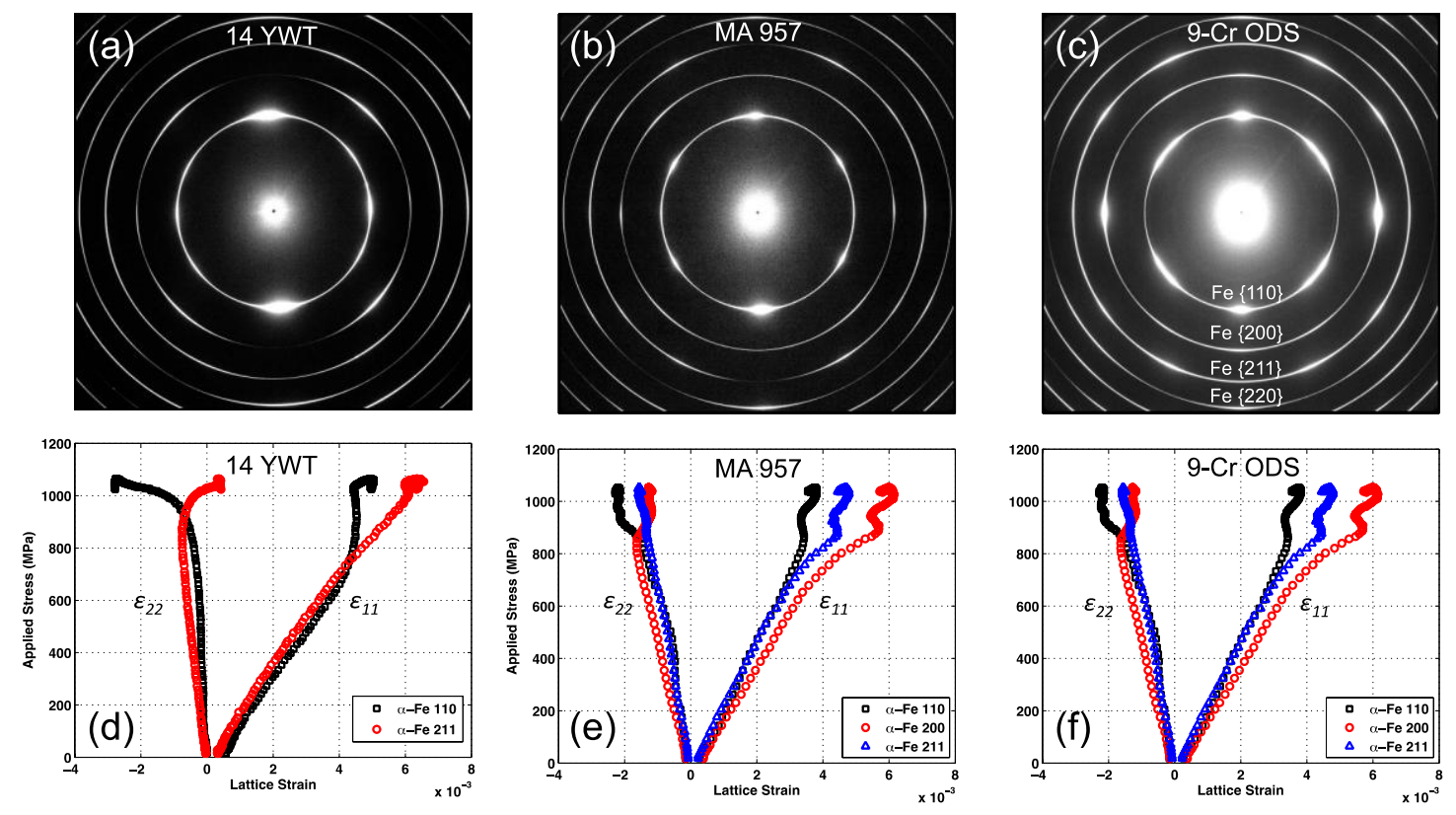

(Figure 5) 


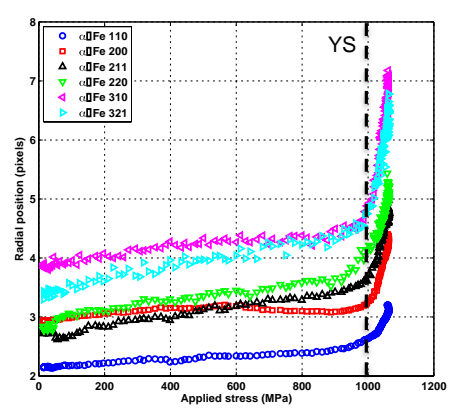

(a)

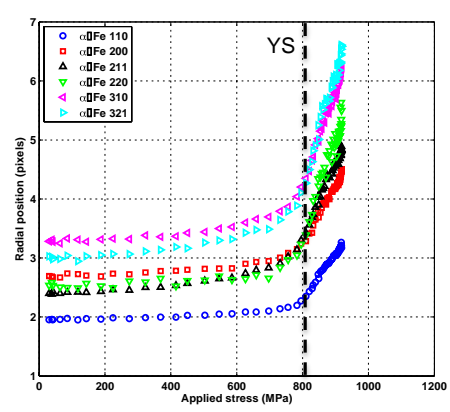

(b)

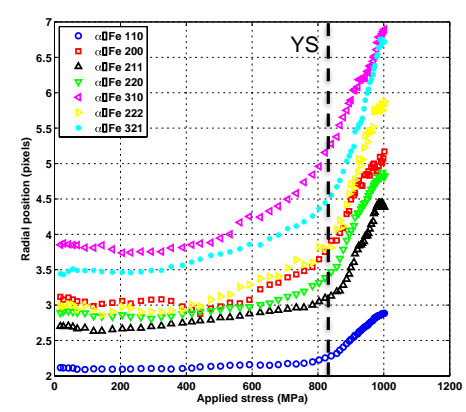

(c)

(Figure 6) 


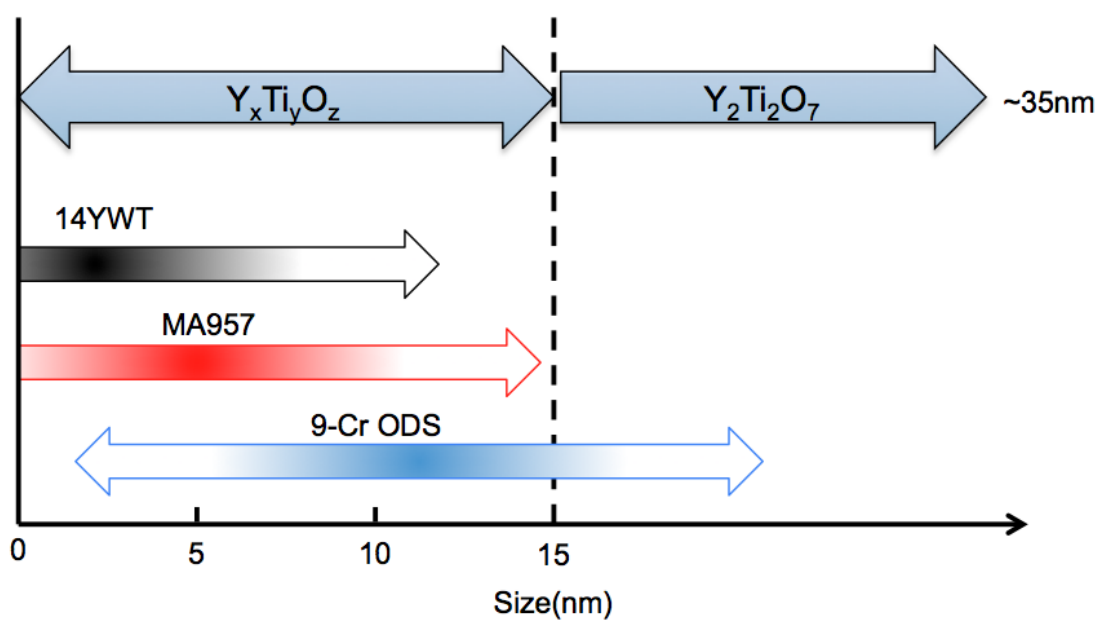

(Figure 7) 

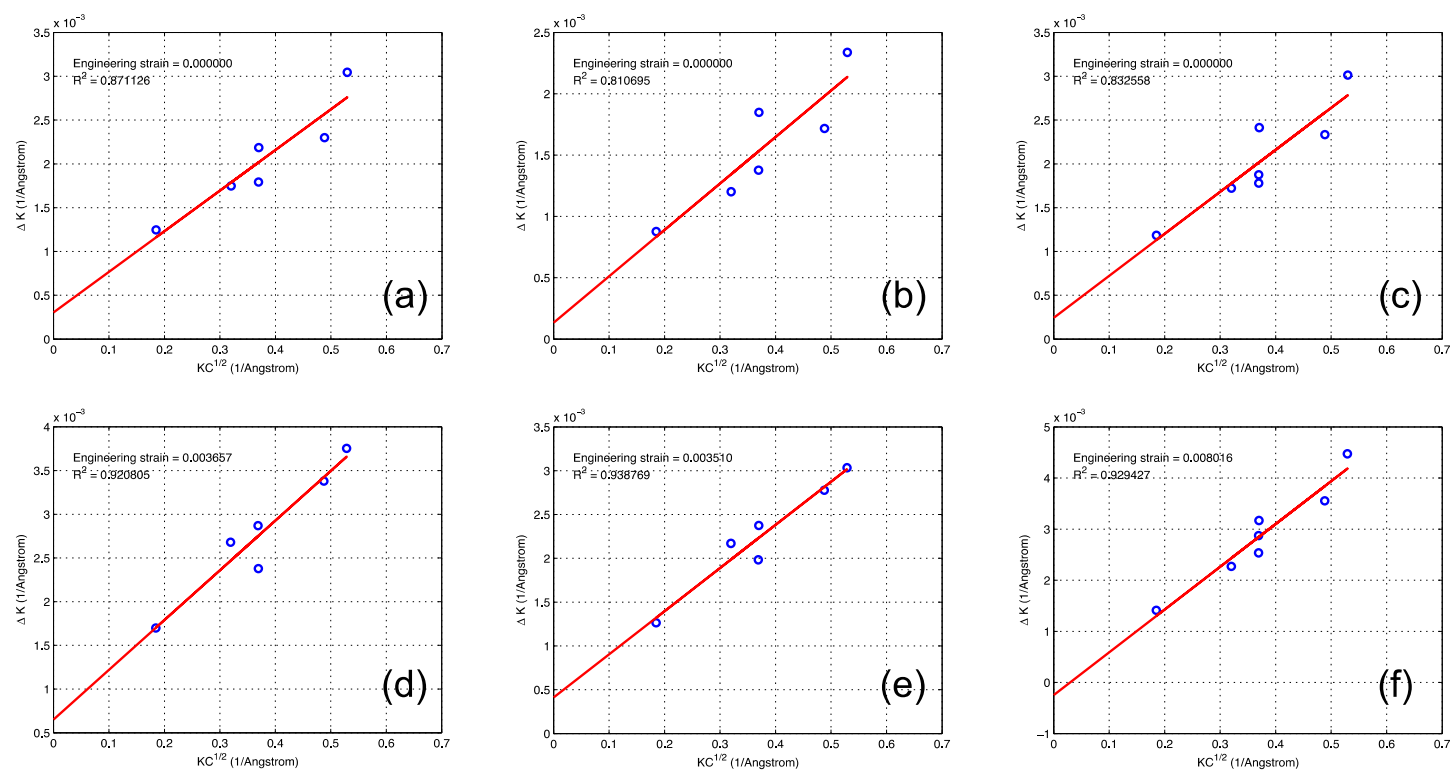

(Figure 8) 


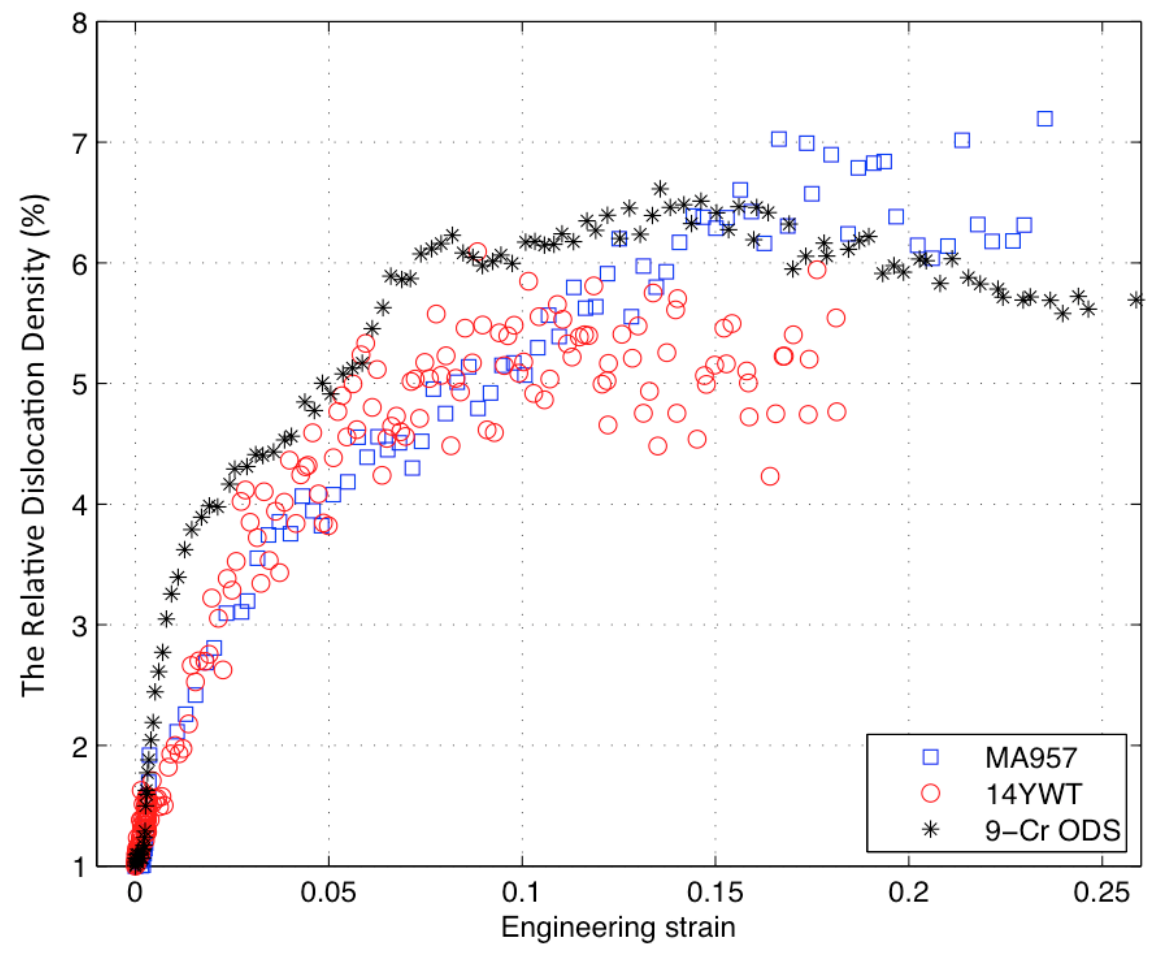

(Figure 9) 


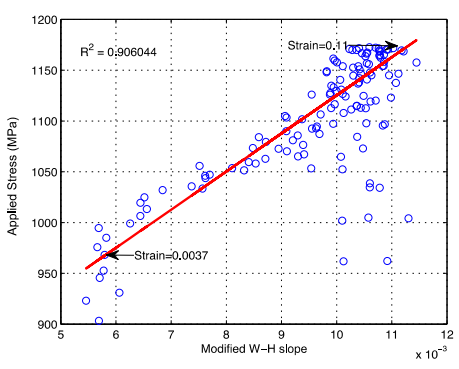

(a)

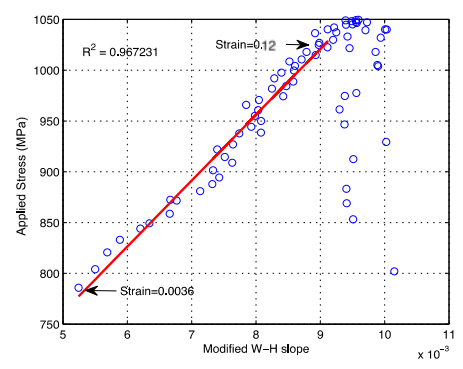

(b)

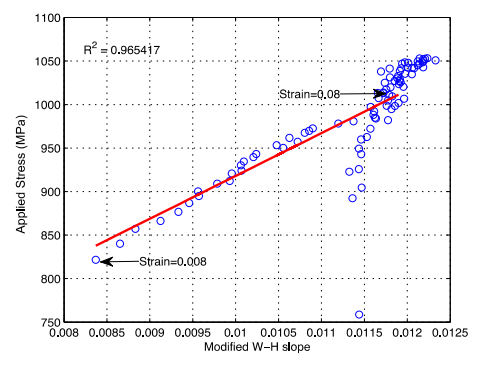

(c)

(Figure 10) 


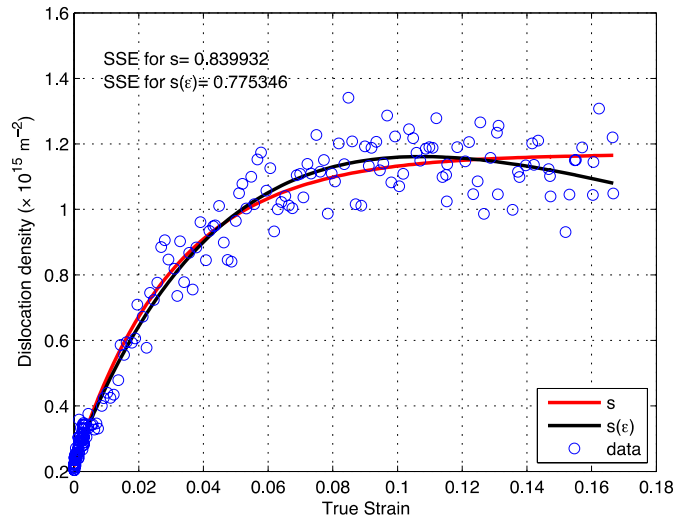

(a)

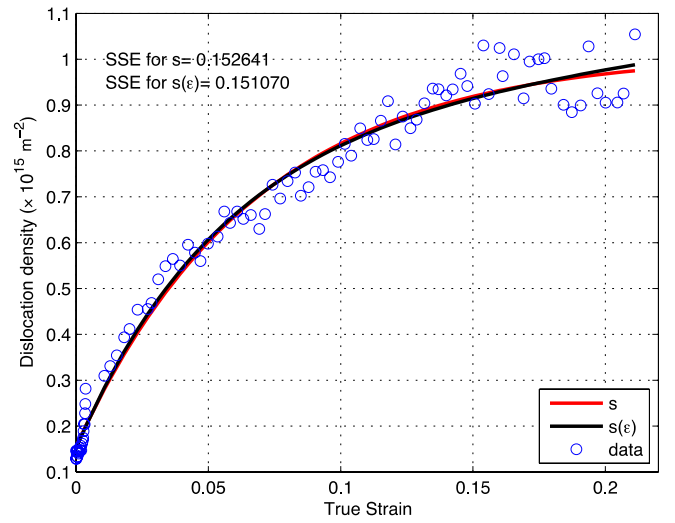

(b)

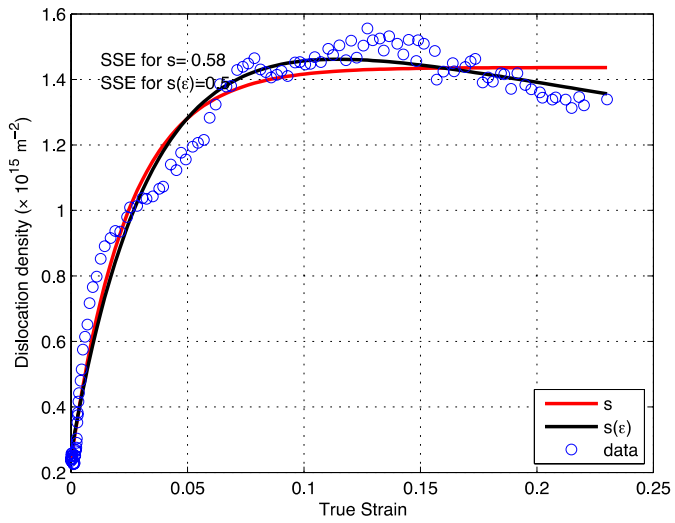

(c)

(Figure 11) 


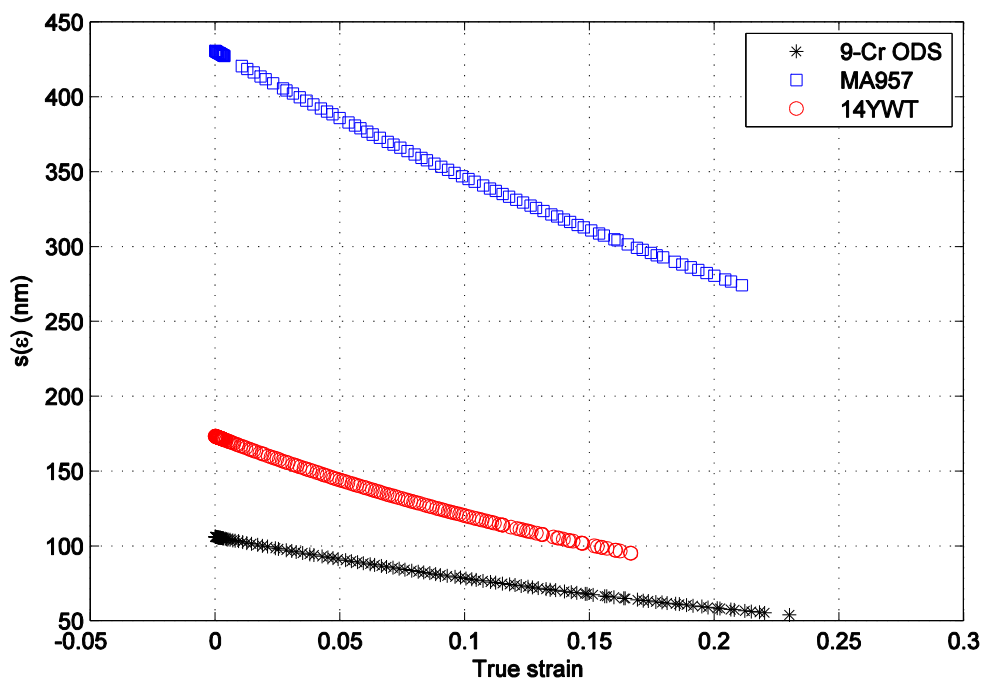

(Figure 12) 
Table 1: Elastic moduli of some reflections of 14YWT, MA957 and 9-Cr ODS. Unit: GPa

\begin{tabular}{lccc}
\hline \hline Reflection & $\mathbf{1 1 0}$ & $\mathbf{2 0 0}$ & $\mathbf{2 1 1}$ \\
\hline 9-Cr ODS & $256 \pm 2$ & $208 \pm 1$ & $239 \pm 2$ \\
MA957 & $222 \pm 3$ & $191 \pm 3$ & NA \\
14YWT & $185 \pm 1$ & NA & $190 \pm 1$ \\
\hline \hline
\end{tabular}

Table 2: Elastic contrast factors $(C)$ of $\alpha$-Fe reflections

\begin{tabular}{lllllllll}
\hline \hline & $\{110\}$ & $\operatorname{Fe}\{200\}$ & $\operatorname{Fe}\{211\}$ & $\operatorname{Fe}\{220\}$ & $\operatorname{Fe}\{310\}$ & $\operatorname{Fe}\{222\}$ & $\operatorname{Fe}\{321\}$ & $\operatorname{Fe}\{\mathbf{4 0 0}\}$ \\
\hline$C$ & 0.1302 & 0.2578 & 0.1302 & 0.1302 & 0.2119 & 0.0877 & 0.1302 & 0.2578 \\
\hline \hline
\end{tabular}

Table 3: Fitting results from Eqs. 6 \& 10

\begin{tabular}{lcccccc}
\hline \hline & \multicolumn{3}{c}{ Eq. 6 } & & \multicolumn{3}{c}{ Eq. 10 } \\
\hline \hline Material & $\boldsymbol{\rho}_{\mathbf{0}}\left(\times \mathbf{1 0}^{\mathbf{1 5}} \mathbf{m}^{\mathbf{2}}\right)$ & $\boldsymbol{s}(\mathbf{n m})$ & $\boldsymbol{\Omega}$ & $\boldsymbol{s}_{\mathbf{0}}(\mathbf{n m})$ & $\boldsymbol{s}_{\boldsymbol{f}}(\mathbf{n m})$ & $\boldsymbol{k}$ \\
& & & & & & \\
\hline 9-Cr ODS & $0.236 \pm 0.03$ & $136.7 \pm 11.9$ & $40.89 \pm 3.83$ & $106 \pm 5.1$ & $9.71 \pm 1.52$ & $3.397 \pm 0.496$ \\
MA957 & $0.155 \pm 0.017$ & $538.9 \pm 40.5$ & $14.7 \pm 1.5$ & $430.6 \pm 31.1$ & $53.3 \pm 42.9$ & $2.537 \pm 2.01$ \\
14YWT & $0.196 \pm 0.015$ & $231 \pm 16$ & $31.68 \pm 5.16$ & $173.2 \pm 12.2$ & $14.03 \pm 4.1$ & $4.053 \pm 1.124$ \\
\hline \hline
\end{tabular}

